\title{
Determining LAMPRey SPECIES COMPOSITION, LARVAl Distribution AND AdUlT Abundance in The DeSChUTES River Subbasin, OREgon
}

2007 Annual Report

Prepared by:

Matt Fox

Jennifer C. Graham

Department of Natural Resources

Confederated Tribes of the Warm Springs Reservation, Oregon

Prepared for:

U.S. Department of Energy

Bonneville Power Administration

Environment, Fish and Wildlife

P.O. Box 3621

Portland, Oregon 97208-3621

Project Number 2002-016-00

Contract Number 34864 


\begin{abstract}
We will report results of an ongoing project in the Deschutes River Subbasin to describe Pacific lamprey (Lampetra tridentata) life history. Project objectives were to determine adult lamprey escapement from Sherars Falls located at Rkm 70.4 and determine lamprey focal spawning areas, spawn timing and habitat through radio telemetry. A mark-recapture study and tribal creel was conducted to determine adult escapement. Lamprey were radio tagged and are currently being mobile, aerial and fixed site tracked to describe spawning. Adult lamprey were collected at Sherars Falls using a long-handled dip net from June - September 2007. The fate of lamprey collected at Sherars Falls was determined based on girth measurements. Fish measuring less than $10.5 \mathrm{~cm}$ received two markings for the mark-recapture estimation while those measuring $10.5 \mathrm{~cm}$ or greater were implanted with radio transmitters. Two-hundred and nine lamprey were marked during first event sampling, 2,501 lamprey inspected for marks and 64 recaptured during second event sampling. We estimate lamprey abundance to be $8,083(6,352-10,279)$ with a relative precision of 19.8. Tribal harvest was 2,303 +/- 88. Escapement was estimated at 5,780 adult lamprey. Thirty-six lamprey received radio transmitters. Lamprey were transported upstream 6.3 Rkm for surgery, held to recover from anesthesia and released. Mobile tracking efforts started mid-July 2007 and are on-going. To date 35 of the 36 lamprey have been detected. Upon release, extensive ground-based tracking was conducted until fish became dormant in mid-October. Since, fixed site downloading and tracking have occurred weekly on the mainstem Deschutes River. Majority of lamprey (88\%) are holding in the mainstem Deschutes River. Three lamprey moved upstream more than 70 Rkms into westside tributaries from August - December. Three moved approximately $18 \mathrm{Rkms}$ downstream of the release site. Tracking will continue through the spawning season when redd characteristics will be measured and reported in the $2008-2009$ annual report.
\end{abstract}




\section{TABLE OF CONTENTS}

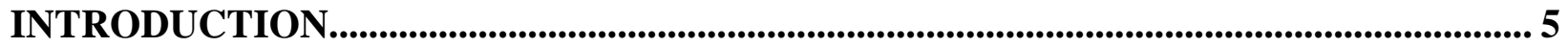

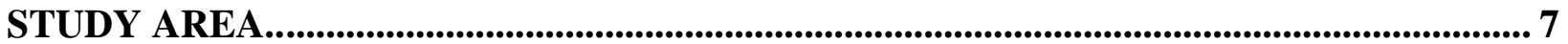

SECTION I: ADULT ESCAPEMENT ESTIMATION AND HARVEST MONITORING .9

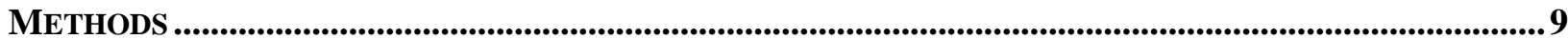

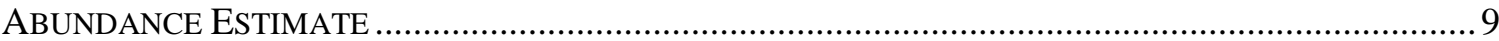

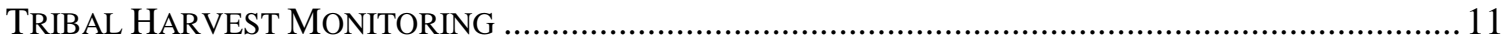

RESULTS AND DISCUSSION ........................................................................................................................... 11

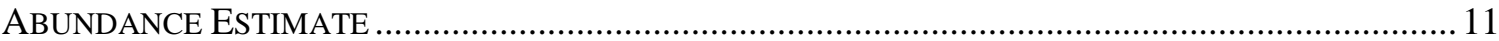

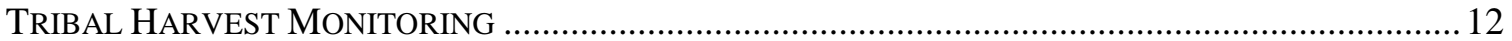

SECTION II: DETERMINE PACIFIC LAMPREY SPAWNING HABITAT IN THE LOWER DESCHUTES RIVER .................................................................. 14

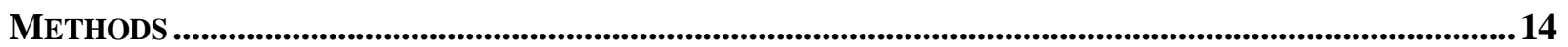

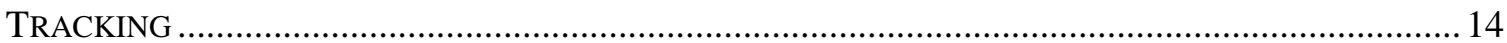

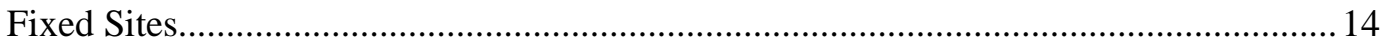

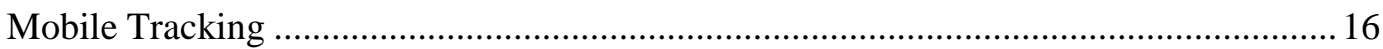

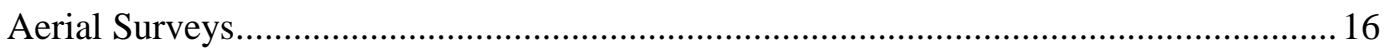

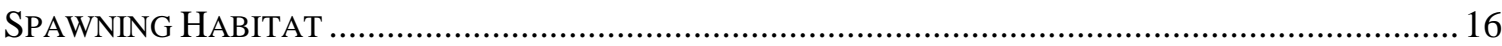

RESULTS \& DISCUSSION..................................................................................................................................... 17

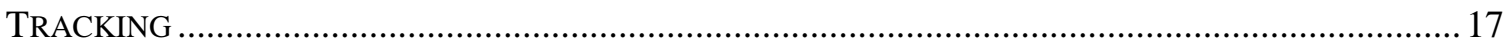

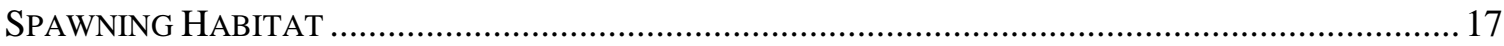

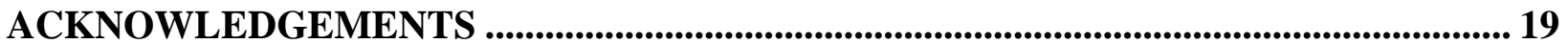

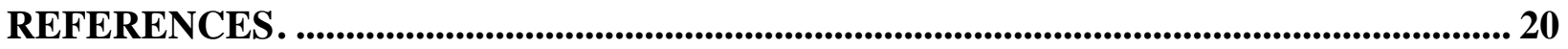




\section{LIST OF FIGURES}

Figure 1. Map of Deschutes River Subbasin and adult Pacific lamprey study locations, 2007 2008 .

Figure 2. Collecting adult lamprey using a long-handled dipnet; (clockwise from the right: Joel Santos dipping for lamprey, Sherars Falls fish ladder, and Joel Santos with long handled dip net) Sherars Falls, lower Deschutes River, 2007. . 10

Figure 3. Cumulative length frequencies of adult Pacific lamprey collected through dipnetting versus harvested at Sherars Falls, lower Deschutes River, 2007.

\section{LIST OF TABLES}

Table 1. Adult Pacific lamprey population estimates in the lower Deschutes River, 2007....... 12

Table 2. Summary of adult Pacific lamprey tribal harvest creel at Sherars Falls, lower Deschutes River, 2007.

Table 3. Adult lamprey capture, release sites and fixed-site telemetry receiver locations in the lower Deschutes River Subbasin, 2007.

Table 4. Biological data for adult Pacific lamprey with radio transmitters, lower Deschutes River, 2007.

\section{LIST OF APPENDICES}

Appendix C Adult Pacific Lamprey Length Statistics and Frequencies in the lower Deschutes River, at Sherars Falls, 2006. 


\section{INTRODUCTION}

Three species of lamprey are endemic to the Columbia River Basin (CRB). Pacific lamprey Lampetra tridentata and river lamprey Lampetra ayresi are anadromous (Beamish 1980), while the western brook lamprey Lampetra richardsoni, completes it's lifecycle in freshwater (Beamish et al. 1982). Limited information on distribution and abundance is available for river lamprey and western brook lamprey within the CRB. Studies in Canada have described river and western brook lamprey biology (Beamish 1987; Beamish 1980; Beamish and Withler 1986; Beamish and Youson 1986; Richards et al. 1982; Vladykov and Follett 1965; and Vladykov and Follett 1958). While Pacific lamprey life history information is available, many critical uncertainties remain (Beamish 1980; Beamish and Levings 1991; Close 1995; Pletcher 1963; Scott and Crossman 1973; van de Wetering 1998). Multiple projects are underway in the CRB to address these uncertainties.

Pacific lamprey were once widely distributed throughout the CRB (Kan 1975; Wydoski and Whitney 1979), but have dramatically declined since the 1940's (Close et al. 1995). Historic information on Pacific lamprey distribution and abundance is limited. Upstream migrant counts at Columbia River dams are used to assess declining trends in Pacific lamprey abundance (Kostow2002). In 1993, the state of Oregon listed Pacific lamprey as a sensitive species and increased their protection status in 1997 (OAR 635-044-0130) (Kostow 2002). During 2003, in response to range-wide declines in lamprey populations, special interest groups throughout Oregon, Washington, and California petitioned United States Fish and Wildlife Service (USFWS), for Pacific lamprey (as well as river lamprey, western brook lamprey, and Kern brook lamprey) to be listed as a threatened or endangered species throughout their range from Mexico to Canada. While USFWS acknowledged declines in Pacific lamprey, it was determined they were not suitable for listing due to their extensive geographic range (50 CFR-17, 77158, December 27, 2004).

Numerous factors may be leading to declines of Pacific lamprey abundance. Poor mainstem passage is cited as a major reason for decline (CBPLTWG 1999; Kostow 2002; Long 1968; Vella et al. 1999a; Vella et al. 1999b). Poor passage efficiencies attribute to apparent decreases in upstream migration (Moser et al. 2002a). Lack of "lamprey friendly" screening at hydroelectric facilities may have sizeable impacts on outmigrating Pacific lamprey (Kostow 2002). Degraded tributary habitat throughout their range including, but not limited to, decreased flows, increased water temperatures, and poor riparian habitat may also explain apparent declines (CBPLTWG 1999; Close et al. 1995).

Adult lamprey spawn in low gradient stream reaches, in gravel, at the tailouts of pools and riffles (Mattson 1949; Pletcher 1963; Kan 1975). Velocities over nests generally range from $0.5-1.0$ $\mathrm{m} / \mathrm{s}$ and spawning depths between $30 \mathrm{~cm}$ and $4 \mathrm{~m}$ (Pletcher 1963, Kan 1975). Nest dimensions are generally between $20-30 \mathrm{~cm}$ in diameter and range in depth from 4-8 cm (Kan 1975, Russell et al. 1987). Nesting dimensions in the Umatilla River were found to have a mean length of $95 \mathrm{~cm}$ with an range of $62-171 \mathrm{~cm}$, mean width of $73 \mathrm{~cm}$ with a range of $31-147 \mathrm{~cm}$, a mean nest depth of $10 \mathrm{~cm}$ with a range of $7-16 \mathrm{~cm}$, and water depths over the nest ranging from $20-40 \mathrm{~cm}$ (Howard and Close 2005). 
Information concerning lamprey spawning habitat requirements in the lower Deschutes River subbasin is limited (Kan 1975; Hammonds 1979; Beamish 1980). Spawning of the Pacific lamprey on the coast of Oregon usually occurs in May while we have observed spawning in the mainstem Deschutes and it's westside tributaries May to July.

The ecological, economic, and cultural significance of Pacific lamprey has been underestimated by many (Close et al. 1995; CRITFC 1995; Kan 1975; NPPC 1995). For Native American tribes of the Pacific Coast, lamprey are an important subsistence, ceremonial, and medicinal resource (Close et al. 1995; CRITFC 1995; Hunn and Selam 1991; Pletcher 1963). For time in memoriam, Confederated Tribes of Warm Springs Reservation, Oregon (CTWSRO) tribal fishers harvest Pacific lamprey at Sherars Falls in the lower Deschutes River. Insufficient numbers of Pacific lamprey for cultural requirements force tribal harvesters to collect lamprey at alternate locations including Willamette Falls, on the Willamette River, located in Oregon City, Oregon.

Baseline information must be collected and analyzed in order to formulate an effective recovery plan for Deschutes River lampreys. Project objectives are to: (1) Conduct a mark-recapture study to estimate adult Pacific lamprey escapement over Sherars Falls and monitor tribal harvest at Sherars Falls; and (2) Determine Pacific lamprey spawning habitat in the lower Deschutes River. 


\section{STUDY AREA}

The lower Deschutes River subbasin is located in central Oregon, draining the east slope of the Cascade mountain range (approximately $6,993 \mathrm{~km}^{2}$ ) with $1,223 \mathrm{~km}$ of perennial streams and $2,317 \mathrm{~km}$ of intermittent streams (Figure 1). A series of hydroelectric dams begin at Rkm 161 . Currently, lamprey passage does not exist at these facilities. Major tributaries of the lower Deschutes River are White River, Warm Springs River and Shitike Creek to the west and to the east Buck Hollow, Bakeoven, and Trout creeks.

Majority of perennial tributaries within the lower Deschutes River subbasin originate within the boundaries of the Confederated Tribes of Warm Springs Reservation. The Reservation covers 240,000 ha on the eastern slopes of the Cascade Mountains. The Reservation boundaries are the crest of the Cascades to the north and west, Deschutes River to the east and Metolius River to the south. The Warm Springs River is the largest watershed within the Reservation, flowing 85 kilometers and draining 54,394 ha. and is the largest tributary to the lower Deschutes River. Major tributaries to the Warm Springs River are Beaver and Mill creeks. Shitike Creek is the third largest tributary to the lower Deschutes River flowing for $48 \mathrm{Rkm}$ and draining 36,000 ha.

The project is implemented in the mainstem Deschutes River reach between Rkm 38.2 to Rkm160 and includes westside tributaries entering this reach. Sherars Falls is located at Rkm 70.4 and is the primary harvest location for CTWSRO tribal members. A fish ladder around Sherars falls provides a convenient site for collecting and marking lamprey in addition to monitoring tribal harvest. Fixed Sites were located in the mainstem Deschutes River, Warm Springs River drainage, and Shitike Creek. We anticipate tracking lamprey to their final spawning locations in Warm Springs River drainage and Shitike Creek. 


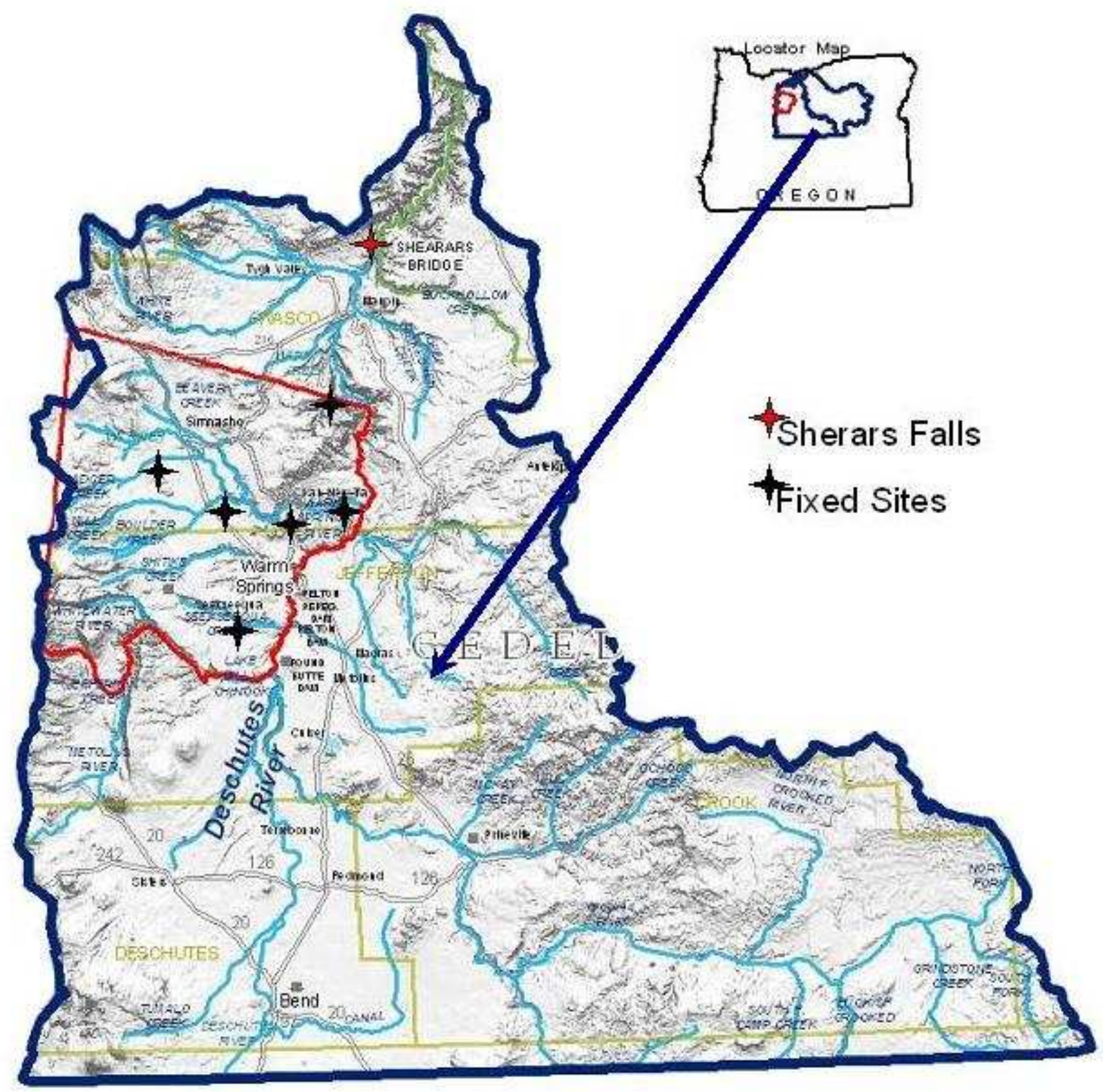

Figure 1. Map of Deschutes River Subbasin and adult Pacific lamprey study locations, 2007 2008. 


\section{SECTION I: ADULT ESCAPEMENT ESTIMATION AND HARVEST MONITORING}

\section{Methods}

\section{Abundance Estimate}

A systematic approach was developed to collect adult Pacific lamprey using a long-handled dip net at Sherars Falls fish ladder located at Rkm 70.4 in the Deschutes River (Figure 2). The fish ladder contains ten pools, each of which were dipped twice per hour for 4 - 8 hours per night. Dipping occurred in the same location during each sampling event. Sampling occurred five randomly selected nights per week from mid June - August. Captured adult Pacific lamprey were fitted with a floy tag, fin clipped, weighed, and total length measured. Sequentially numbered floy tags were anchored approximately $0.5 \mathrm{~cm}$ inferior to the posterior of the dorsal fin. Each lamprey received a secondary mark which consisted of a fin clip at the posterior end of the dorsal fin. Once marked, lamprey were transported approximately $2 \mathrm{Rkm}$ downstream and released. Subsequently captured lamprey were inspected for tag presence and fin clip. Recaptures were recorded and released upstream of the fish ladder. A primary tag retention rate was calculated based on tag presence or tag wound and fin clip. Abundance was estimated using Chapman's modification of the Petersen estimate (Seber 1982). Estimated abundance ( $\left.{ }^{*}\right)$ was derived from:

$$
N^{*}=\frac{(M+1)(C+1)}{(R+1)}-1
$$

Where $M$ is number of fish marked in first event sampling, $C$ is total fish inspected for marks during second event sampling and $R$ is the number of fish recaptured.

Chapman's modified estimate uses a Poisson approximation to the hypergeometric distribution and approaches a minimum variance unbiased estimator of population size with variance approximated by:

$$
\begin{aligned}
& V\left(N^{*}\right)=N^{2}\left(\mu^{-1}+2 \mu^{-2}+6 \mu^{-3}\right) \\
& \text { where } \mu=M C / N
\end{aligned}
$$

For $N^{*}$ to be a suitable estimate the following assumptions must be met:

1. All Pacific lamprey have an equal probability of being marked at Sherars Falls fish ladder; or

2. All Pacific lamprey have an equal probability of being inspected for marks; or

3. Marked fish mix completely with unmarked fish between sampling events; and

4. No recruitment into the population between sampling events; and

5. No sampling-induced behavior or mortality; and

6. Fish do not lose their marks and marks are recognizable. 


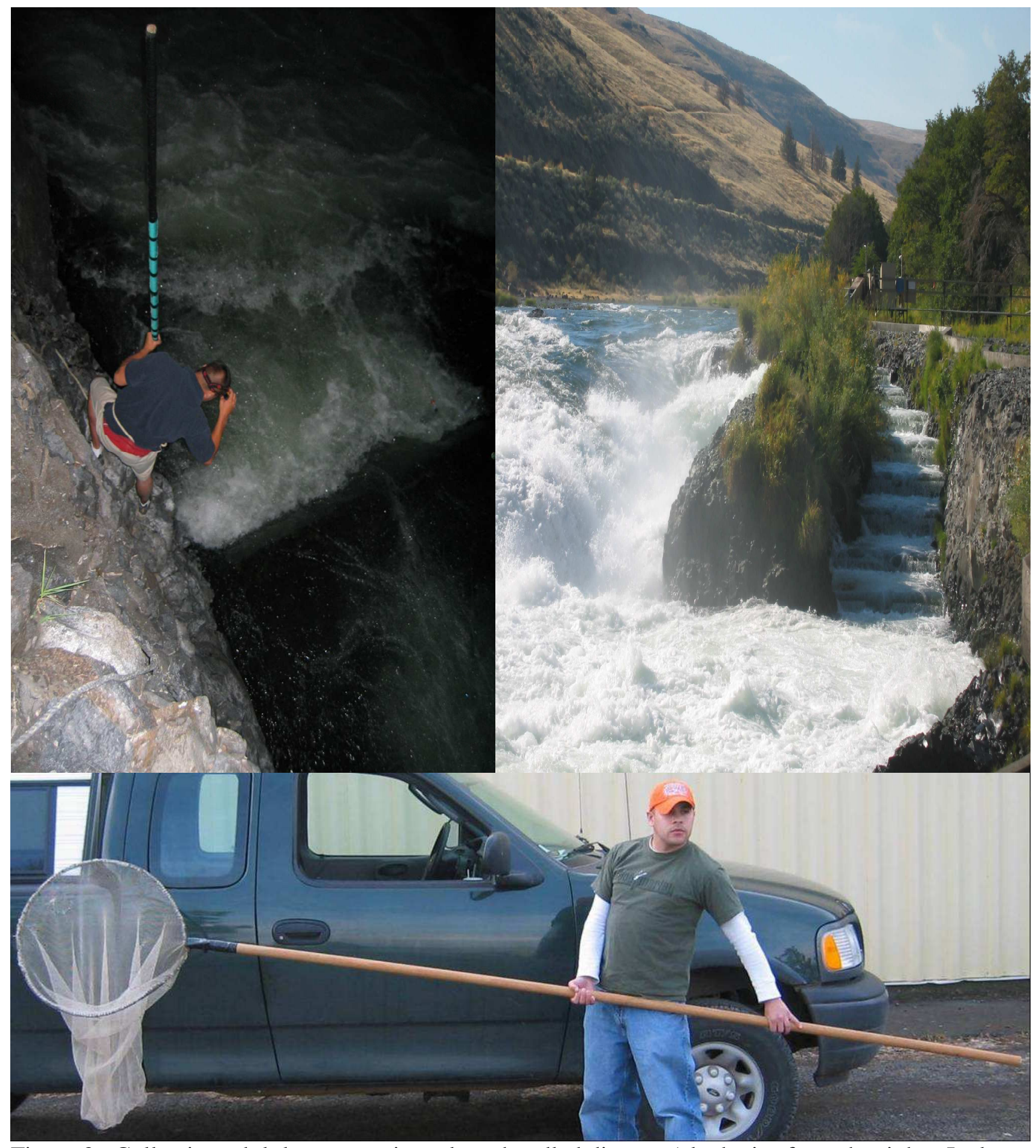

Figure 2. Collecting adult lamprey using a long-handled dip net; (clockwise from the right: Joel Santos dipping for lamprey, Sherars Falls fish ladder, and Joel Santos with long handled dip net) Sherars Falls, lower Deschutes River, 2007. 
To determine if assumptions 1 and 2 were violated, a chi-square test $(\alpha=0.05)$ was performed comparing length distributions between dipnetting and tribal harvest. To ensure mixing, all marked Pacific lamprey were transported and released approximately $2 \mathrm{Rkm}$ downstream of the initial capture site (assumption 3). To minimize potential for fish to be introduced into the experimental population, tagging was conducted throughout the majority of the run; therefore assumption 4 was not violated. It is possible for lamprey to enter the experimental population after first event sampling is completed. However, first event sampling was suspended when lamprey present in the fish ladder was near zero. There is no direct mortality associated with dipnetting and indirect mortality cannot be evaluated but is assumed negligible (assumption 5). Only fish in good condition were marked and released. No deceased, marked lamprey were reported downstream of the first event sampling site during the marking phase of the experiment. To reduce the potential for tag loss, secondary marks were applied (assumption 6). Tag loss was determined by presence of a tag wound and fin clip.

\section{Tribal Harvest Monitoring}

In conjunction with marking and recapturing adult lamprey, a single access site creel survey was conducted to estimate tribal harvest of adult Pacific lamprey. Interviews were conducted five randomly selected nights per week from July - mid September. Creel surveys occurred from 9 pm until tribal fisherman completed collection or $3 \mathrm{am}$, whichever occurred first. Samplers examined all harvested lamprey for marks and recorded total lengths. Numbers of marked (nonexpanded numbers) and unmarked lamprey were recorded on datasheets. Creel numbers were expanded to estimate total harvest and $95 \%$ confidence intervals generated.

Total effort and harvest was expanded from each sampling day by:

$$
\begin{array}{ll}
\text { Total Effort: } & \hat{\mathrm{E}}=\sum_{i=1}^{n}\left(e_{i} / \boldsymbol{\pi}_{i}\right) \\
\text { Total Catch: } & \hat{C}=\sum_{i=1}^{n}\left(c_{i} / \pi_{i}\right)
\end{array}
$$

Variance was approximated each sampling week by:

$$
\operatorname{Var}\left(\hat{E}_{1}\right) \approx N_{1}^{2} \operatorname{Var}\left(\hat{e}_{1}\right)
$$

Weekly variances were summed to estimate total variance of the harvest estimate.

\section{Results and Discussion}

\section{Abundance Estimate}

From 16 June to 21 August, 209 adult Pacific lamprey were tagged, 64 recaptured and 2,501 inspected for marks (Table 1). Our preliminary population estimate for adult Pacific lamprey in the Deschutes River during 2007 was 8,083 (6,352 - 10,279). The preliminary estimate of adult Pacific lamprey escapement at Sherars Falls was estimated at 5,780. 
Table 1. Adult Pacific lamprey population estimates in the lower Deschutes River, 2007.

\begin{tabular}{cccccccc} 
Year & $\begin{array}{c}\text { No. } \\
\text { Tagged }\end{array}$ & $\begin{array}{c}\text { No. } \\
\text { Inspected }\end{array}$ & $\begin{array}{c}\text { No. } \\
\text { Recoveries }\end{array}$ & $\begin{array}{c}\text { Population } \\
\text { Size }\end{array}$ & Variance & $\begin{array}{c}\text { Standard } \\
\text { Error }\end{array}$ & $\begin{array}{c}\text { Relative } \\
\text { Precision }\end{array}$ \\
\hline 2007 & 209 & 2,501 & 64 & 8,083 & 665,824 & 816 & 19.8 \\
\hline
\end{tabular}

Sixty-four (30.62\%) lamprey were recaptured. Of those, 36 (56.25\%), 19 (29.69\%) and nine $(14.06 \%)$, were caught through tribal creel, tribal member tag returns and long handled dipnetting, respectively. No significant difference was found between marked and inspected adult Pacific lamprey lengths $\left(X^{2}=21.297 ; 7 \mathrm{df} ; \mathrm{P}=0.003\right)$ (Figure 3).

All lamprey received individually numbered floy tags and a fin clip. Tag retention rates were calculated based on presence of a fin clip and tag wound. Fifty-four of $63(84.38 \%)$ recaptured lamprey retained their tags. We have evaluated tag retention since 2003. Tag retention rates have ranged from $85.29 \%$ - 90.34\%. Mean movement rate from Buckhollow Landing to Sherars Falls was 3.66 days based on thirty-one recaptured fish with number tags.

\section{Tribal Harvest Monitoring}

A total of 40 creel interviews were conducted from 19 June - 11 September, 2007 (Table 2). Four hundred and seventy-two adult Pacific lamprey were measured and inspected. Preliminary estimates of tribal harvest are 2,303 (+/- 88). Based on preliminary population estimates and tribal harvest we estimated an exploitation rate of $28.5 \%$. Descriptive statistics and length frequency histograms can be found in Appendix A. 


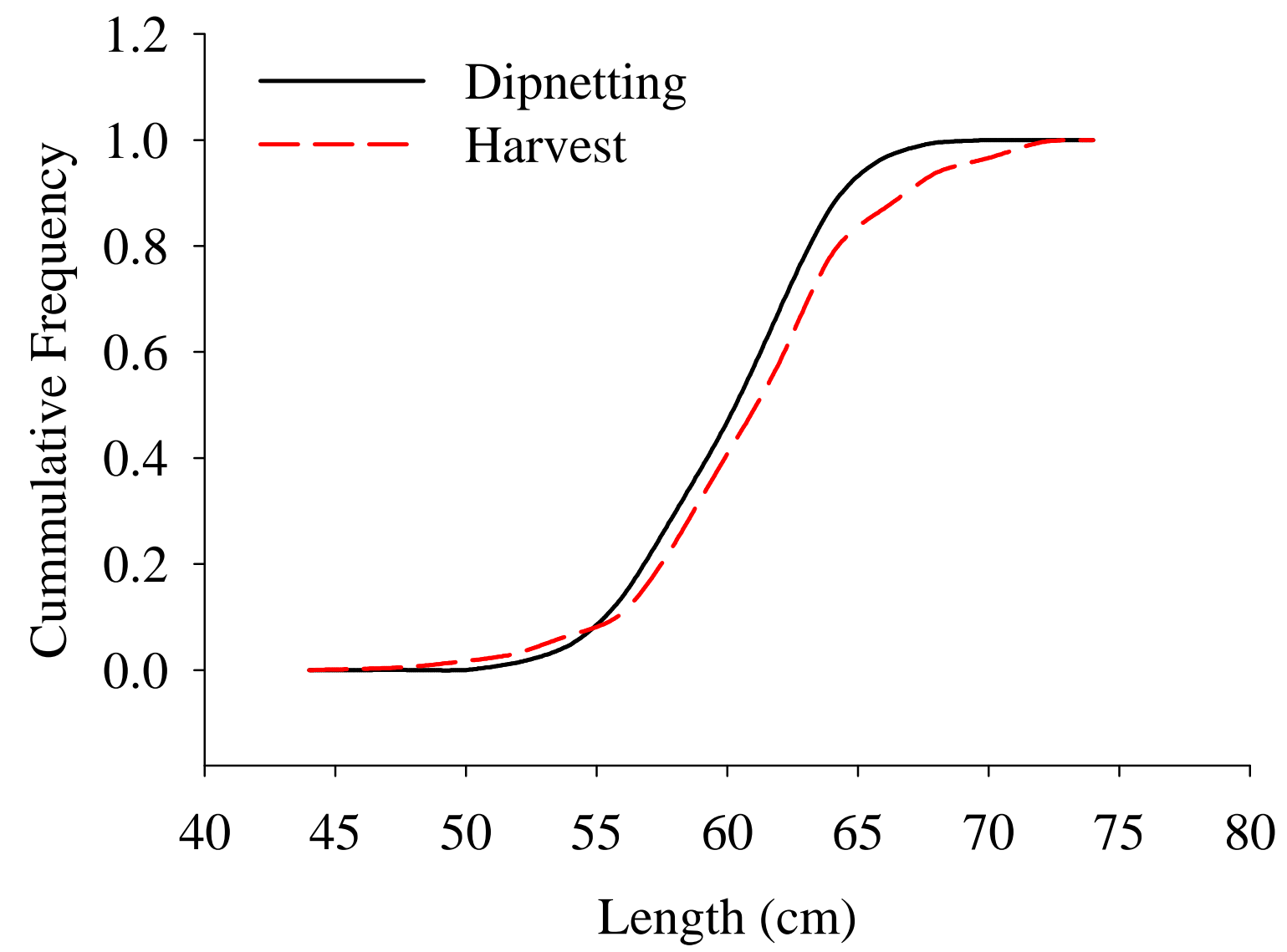

Figure 3. Cumulative length frequencies of adult Pacific lamprey collected through dipnetting versus harvested at Sherars Falls, lower Deschutes River, 2007.

Table 2. Summary of adult Pacific lamprey tribal harvest creel at Sherars Falls, lower Deschutes River, 2007.

\begin{tabular}{ccccc} 
Year & Dates & $\begin{array}{l}\text { Interviews } \\
\text { Conducted }\end{array}$ & $\begin{array}{c}\text { Lamprey } \\
\text { Creeled }\end{array}$ & $\begin{array}{c}\text { Estimated } \\
\text { Harvest }\end{array}$ \\
\hline 2007 & $6 / 19-9 / 11$ & 40 & 2,501 & $2,302+/-88$ \\
\hline
\end{tabular}




\section{SECTION II: DETERMINE PACIFIC LAMPREY SPAWNING HABITAT IN THE LOWER DESCHUTES RIVER}

\section{Methods}

From 11 July to 22 August 2007 adult Pacific lamprey were fitted with radio tags. Lamprey with a girth measurement of $10.5 \mathrm{~cm}$ or greater were collected at Sherars Falls fish ladder and transported upstream for holding and transmitter implantation. Individuals were held up to 48 hours prior to surgery. Unique frequency transmitters (Lotek Engineering, Inc., Ontario, Canada; model NTC-6-2) were surgically implanted into adult lamprey. Of the 36 individuals radio tagged, 29 were released at Lower Blue Hole recreation site (LBH) at Rkm 77.8 and seven at White River Campground (WRCG, Rkm 75.3). Release sites were selected upstream of Sherars Falls to minimize potential for radio tagged lamprey to move below the falls or be captured by Tribal fishers. Sex, total length, weight and mid-girth measurements were recorded prior to surgery.

Radio transmitters were surgically implanted using methods developed by NOAA Fisheries (Bayer et al. 2000). A buffered solution of Eugenol (5 mL:50 L water) was used to anesthetize lamprey prior to the implantation procedure. Lamprey were moved from anesthesia and placed into a large cooler with a cylindrical tube to hold individuals during surgical procedure. Lamprey were placed anterior side down in the trough and bathed in a solution of buffered eugenol (1 $\mathrm{mL}: 16 \mathrm{~L}$ water). An incision approximately $2 \mathrm{~cm}$ in length was made longitudinally, just off the mid-line. A sheathed catheter was inserted into the incision and pierced through the musculature, approximately $1-3 \mathrm{~cm}$ posterior of the incision. The catheter was removed, leaving the sheath. Transmitters were inserted antenna first through the sheath, into the body cavity and then the sheath was removed. Three evenly spaced sutures were completed close along the incision using $4 / 0$ absorbent suture material. Once suturing was completed, oxytetracycline $(100 \mathrm{mg} / \mathrm{ml})$ was injected under the sutures. Antibacterial ointment was placed along the incision and sutures. After surgery lamprey were moved into a covered, aerated holding box to recover. All lamprey were released during or post sunset.

\section{Tracking}

Fixed Sites

Fixed-site telemetry receiving stations were used to monitor movement of radio tagged lamprey in the lower Deschutes River Subbasin. Six fixed sites capture transmitter signals from passing lamprey along the lower Deschutes River, Warm Springs River, Badger, Shitike and Beaver Creeks (Table 3; Figure 1). Fixed site receivers record data continuously throughout the year. Data was downloaded from receivers as needed (i.e. weekly during movement periods, monthly during holding periods). Tag code, date, time, and signal strength was collected when downloaded. Receiving stations were calibrated twice in 2007 to ensure detection of passage prior to peak movements. Badger Creek fixed site was removed 3 December 2007 due to high water and returned in early April 2008. Water temperature data loggers (Onset Computer Corporation, Hobo Water TempPro ${ }^{\mathrm{TM}}$ ) were place adjacent to each fixed site. Data logging will continue through the completion of spawning to record seasonal variations in water temperature and how they influence lamprey movements. 
Table 3. Adult lamprey capture, release sites and fixed-site telemetry receiver locations in the lower Deschutes River Subbasin, 2007.

\begin{tabular}{|c|c|c|c|}
\hline Site Name & Stream & $\mathrm{Rkm}$ & Status \\
\hline Sherars Falls (Capture Location) & Deschutes River & 70.4 & Capture Location \\
\hline White River Campground & Deschutes River & 75.3 & Release Site \\
\hline Lower Blue Hole Rec. Site & Deschutes River & 77.8 & Release Site \\
\hline Dant & Deschutes River & 99.8 & Fixed Site \\
\hline PRB Reregulation Dam & Deschutes River & 160 & Passage Barrier \\
\hline Mouth of Warm Springs & Warm Springs River & 0.1 & Fixed Site \\
\hline Warm Springs Fish Hatchery & Warm Springs River & 10.7 & Temp Fixed Site \\
\hline Island & $\begin{array}{c}\text { Warm Springs River } \\
\text { Beaver Creek }\end{array}$ & $\begin{array}{l}19.3 \\
0.3\end{array}$ & Fixed Site \\
\hline B-100 & Badger Creek & 3.0 & Fixed Site \\
\hline Warm Springs Forest Products & Shitike Creek & 1.7 & Fixed Site \\
\hline
\end{tabular}




\section{Mobile Tracking}

Ground surveys consisted of a mobile tracking receiver and hand-held antenna. Upon release of first radio tagged lamprey, ground surveys were conducted frequently as fish move. Once holding was established, surveys were conducted weekly or biweekly. Tracking was accomplished by vehicle, foot and kayak to pinpoint lamprey locations. Global Positioning System (GPS) coordinates were taken when fish located. Additional data collected included: time, date, location $(\mathrm{Rkm})$ of detection, general river channel description, weather and digital photographs.

\section{Aerial Surveys}

Aerial surveys were conducted from chartered, fixed-wing aircraft equipped with aerial telemetry antennae. Two surveys of the Warm Springs River and Beaver Creek was completed 3 October 2007 and 12 February 2008. We plan to conduct reconnaissance flights monthly from April July 2008.

\section{Spawning Habitat}

When radio tagged lamprey begin redd building or spawning behavior is observed, locations will be recorded for further observation. The following week another survey will be conducted to determine if spawning occurred. Radio transmitters will be retrieved if possible. Thermograph data will be retrieved after spawning is complete. Data will be summarized using Eel River Water Temperature Analysis Program V.97.8 ${ }^{\mathrm{C}}$. Redd and spawning habitat characteristics will be collected as described below.

For redds the following measurements will be collected:
$\checkmark$ Nest dimensions (length, width and depth to nearest $\mathrm{cm}$ )
$\checkmark$ Current velocity (recorded $5 \mathrm{~cm}$ from substrate at and $60 \%$ depth for head, middle and tail)
$\checkmark$ Water depth (recorded at head, middle and tail)
$\checkmark$ Substrate type (\% composition at head, middle and tail)
$\checkmark$ Water temperature
$\checkmark$ Distance from adjacent redds

For spawning habitat the following measurements will be collected:
$\checkmark$ Total area available
$\checkmark$ Average water depth
$\checkmark$ Bankfull width
$\checkmark$ Wetted channel width
$\checkmark$ Channel type
$\checkmark$ Substrate composition
$\checkmark$ Riparian Composition
$\checkmark$ Canopy Cover 


\section{Results \& Discussion}

A total of 36 lamprey were implanted with radio transmitters. Lengths ranged from $61.0-71.0$ $\mathrm{cm}$ with a mean of $65.7 \mathrm{~cm}$. Minimum, maximum and mean girth measurements were $10.5 \mathrm{~cm}$, $13.0 \mathrm{~cm}$ and $11.0 \mathrm{~cm}$, respectively. Weights varied from $350.0-560.0 \mathrm{~g}$ with a mean of $464.3 \mathrm{~g}$ (Table 4).

\section{Tracking}

Currently, lamprey in the Deschutes River are distributed from Rkm 38.2 - Rkm 141.6. Thirtyfive of the 36 (99\%) radio tagged lamprey have been coded since release. Lamprey No. 9 released at WRCG has never been located. The majority of lamprey (47\%) are over-wintering within a five mile radius of release sites. During over-wintering, our ability to identify radio tagged lamprey decreases as the signal may not be detectable in areas with deep water, heavy wooded debris, or boulders.

Personal observation suggest Deschutes River lamprey hold in fast water sections (White River Rapids, Oak Springs Rapids, Boxcar Rapids) or tailout areas; while lamprey in tributaries overwinter in riffles and glides. The size of the Deschutes River prohibits pinpointing exact locations for individual tagged fish.

Mean rate of passage through Dant fixed site (DFS) was $1 \mathrm{hr} 25 \mathrm{~min}$. Mean rate of passage through WSMFS was 16.5 min. All fixed site movement (DFS and WSMFS) occurred at night with a maximum time of 9:24pm, minimun time of 3:24am and a mean time of 12:26am.

\section{Spawning Habitat}

Spawning habitat characteristics will be compared among all documented spawning sites to determine if lamprey demonstrate an affinity for certain stream habitat types. Descriptive statistics will be used to summarize redd and spawning habitat characteristics. Analysis of variance will be performed to detect differences among spawning groups by streams.

When spawning habitat is described results will be used to identify suitable habitat in other stream reaches and tributaries that are not occupied by lamprey. If sufficient spawning and larval rearing habitat is available, future work plans may include re-introduction of adult lamprey to these areas as a restoration strategy.

Radio tagging will continue in 2008. Mobile tracking will remain on its current schedule and aerial surveys will resume in April. Spawning surveys will begin in spring of 2008 and habitat data will be included in 2008 - 2009 annual report. 
Table 4. Biological data for adult Pacific lamprey with radio transmitters, lower Deschutes River, 2007.

\begin{tabular}{lcccc} 
Biological Data & $\mathrm{N}$ & Mean & Max & Min \\
\hline Weight $(\mathrm{g})$ & 36 & 464.3 & 560.0 & 350.0 \\
Length (cm) & 36 & 65.7 & 71.0 & 61.0 \\
Girth (cm) & 36 & 11.0 & 13.0 & 10.5 \\
\hline
\end{tabular}




\section{ACKNOWLEDGEMENTS}

We thank the many individuals and agencies whom assisted with this project: Joel Santos, Sterling Kalama and other CTWSRO Natural Resources employees for their many hours of field work; Debbie Docherty (BPA) for contract administration; Members of the Lamprey Technical Working Group for technical assistance; Bonneville Power Administration for providing funds; and the people of CTWSRO for their encouragement and support. 


\section{REFERENCES}

Bayer, J. M., M. H. Meeuwig, and J. G. Seelye. 2000. Identification of larval Pacific lamprey (Lampetra tridentata), river lamprey (L. ayersi), and western brook lamprey (L. richardsoni) and thermal requirements of early life history stages of lamprey. Annual report to Bonneville Power Administration, Project Number 2000-029, Portland, Oregon.

Bayer, J. M., M. H. Meeuwig, and J. G. Seelye. 2001. Identification of larval Pacific lamprey (Lampetra tridentata), river lamprey (L. ayersi), and western brook lamprey (L. richardsoni) and thermal requirements of early life history stages of lamprey. Annual report to Bonneville Power Administration, Project Number 2000-029, Portland, Oregon.

Bayer, J. M., M. H. Meeuwig, and J. G. Seelye. 2002. Identification of larval Pacific lamprey(Lampetra tridentata), river lamprey (L. ayersi), and western brook lamprey (L. richardsoni) and thermal requirements of early life history stages of lamprey. Annual report to Bonneville Power Administration, Project Number 2000-029, Portland, Oregon.

Beamish, R. J. 1980. Adult biology of the river lamprey (Lampetra ayresi) and the Pacific lamprey (Lampetra tridentata) from the Pacific coast of Canada. Canadian Journal of Fisheries and Aquatic Sciences 37: 1906-1923.

Beamish, R. J. 1982. Lampetra macrostama, a new species of freshwater parasitic lamprey from the west coast of Canada. Canadian Journal of Fisheries and Aquatic Sciences 39: 736747.

Beamish, R. J. 1987. Evidence that parasitic and nonparasistic life history types are produced by one population of lamprey. Canadian Journal of Fisheries and Aquatic Sciences 44: 17791782.

Beamish, R. J. and C. D. Levings. 1991. Abundance and freshwater migration of the anadromous parasitic lamprey, Lampetra tridentata, in a tributary of the Fraser River, British Columbia. Canadian Journal of Fisheries and Aquatic Sciences 48:1250-1263.

Beamish, R. J. and R. E. Withler. 1986. A polymorphic population of lamprey that may produce parasitic and a nonparasitic varieties. In Info-Pacific Fish Biology; Proceedings of the Second International Conference on Indo-Pacific Fishes, ed. By Uyeno et al. Ichthyology Society of Japan, Tokyo. Pp. 31-49.

Beamish, R. J. and J. H. Youson. 1986. Life history and abundance of young adult Lampetra ayresi in the Fraser River and their possible Impact on Salmon and Herring Sticks in the Strait of Georgia. Canadian Journal of Fisheries and Aquatic Sciences 44: 525-537.

Bond, C. L. 1979. Biology of Fishes. Saunders, Philadelphia. 
CBPLTWG. 1999. Planning of the Columbia Basin Pacific Lamprey projects and needs. Report to Northwest Power Planning Council and Bonneville Power Administration, Portland, Oregon.

Close, D. A. 1998. Pacific lamprey research and restoration project. Annual report to Bonneville Power Administration, Project \#94-026, Portland, Oregon.

Close, D. 1999. Pacific lamprey research and restoration project. Annual report to Bonneville Power Administration, Project \#94-026, Portland, Oregon.

Close, D. A. 2000. Pacific lamprey research and restoration project. Annual report to Bonneville Power Administration, Project \#94-026, Portland, Oregon.

Close, D. A. 2001. Pacific lamprey research and restoration project. Annual report to Bonneville Power Administration, Project \#94-026, Portland, Oregon.

Close, D. A., M. Fitzpatrick, H. Li, B. Parker, D. Hatch, and G. James. 1995. Status report of the Pacific lamprey (Lampetra tridentata) in the Columbia River Basin. BPA Report DOE/BP-39067-1, U.S. Department of Energy, Bonneville Power Administration, Portland, Oregon.

Close, D. A. and K. K. Aronsuu. 2002. Pacific lamprey research and restoration project. Annual report to Bonneville Power Administration, Project \#94-026, Portland, Oregon.

Close, D. A., M. S. Fitzpatrick, and H. W. Li. 2002. The ecological and cultural importance of a species at risk of extinction, Pacific lamprey. Fisheries 27:19-25.

Cochnauer, T. and C. Claire. 2000. Evaluate Status of Pacific lamprey in the Clearwater RiverDrainage, Idaho. Annual Report to Bonneville Power Administration, Project \#00028, Portland, Oregon.

CRITFC. 1995. WY-KAN-USH-MI WA-KISH-WIT. The Columbia River anadromous fish restoration plan of the Nez Perce, Umatilla, Warm Springs, and Yakama Tribes. Portland, Oregon.

Hammonds, R. J. 1979. Larval biology of the Pacific lamprey, Entosphenus tridentatus (Gairdner), of the Potlatch River, Idaho. M.S. thesis, University of Idaho, Moscow, Idaho.

Hansen, M. J., J. V. Adams, D. W. Cuddy, J. M. Richards, M. F. Fodale, G. L. Larson, D. J. Ollila, J. W. Slade, T. B. Steeves, R. J. Young and A. Zerrenner. 2003. Optimizing Larval Assessment to Support Sea Lamprey Control in the Great Lakes. J. Great Lakes Res. 29 (Supplement 1): 766-782.

Hunn, E. S. and J. Selam. 1991. Nch'i-Wana "The Big River": Mid-Columbia Indians and theirlands. University of Washington Press, Seattle, Washington. 
Jackson, A. D, P. D. Kissner, D. R. Hatch, B. L. Parker, D. A. Close, M. S. Fitzpatrick, and H. Li. 1996. Pacific lamprey research and restoration. Annual report to Bonneville Power Administration, Project Number 94-026, Portland, Oregon.

Jackson, A. D., D. R. Hatch, B. L. Parker, D. A. Close, M. S. Fitzpatrick, and H. Li. 1997. Pacific lamprey research and restoration. Annual report to Bonneville Power Administration, Project Number 94-026, Portland, Oregon.

Kan T. T. 1975. Systematics, variation, distribution, and biology of lamprey of the genus Lampetra in Oregon. PhD. Dissertation, Oregon State University, Corvallis, Oregon.

Kostow, K. 2002. Oregon lamprey: Natural history status and problem analysis. Oregon Department of Fish and Wildlife, Portland, Oregon.

Long, C. W. 1968. Diel movement and vertical distribution of juvenile anadromous fish in turbine intakes. Fishery Bulletin 66:599-609.

Moser, M. L., L. C. Stuehrenberg, W. Cavender, S. G. McCarthy, and T. C. Bjornn. 2002. Radop Telemetry investigations of adult Pacific lamprey migration behavior: evaluation of modifications to improve passage at Bonneville Dam, 2000. Annual Report of Research to the U.S. Army Corp of Engineers, Portland District, Portland, Oregon.

Ocker, P. A., L. W. Stuehrenberg, M. L. Moser, A. L. Matter, J. J. Vella, B. P. Sanford, T. C. Bjornn, and K. R. Tolotti. 2001. Monitoring adult Pacific lamprey (Lampetra tridentata) migration behavior in the lower Columbia River using radiotelemetry, 1998-1999. Annual Report of Research to the U.S. Army Corp of Engineers, Portland District, Portland, Oregon.

O’Neal, L. B. 1987. AbP-2 operator's manual. Instrumentation Systems Center, University of Wisconsin, Madison.

Pajo, T. A. and J. G. Weise. 1994. Estimating populations of larval sea lamprey with electrofishing sampling methods. North American Journal of Fisheries Management 14:580-587.

Pletcher T. F. 1963. The life history and distribution of lamprey in the Salmon and certain other rivers in British Columbia, Canada. M.Sc. thesis, University of British Columbia, Vancouver, B.C.

Richards, J. E. 1980. Freshwater life history of the anadromous Pacific lamprey Lampetra tridentata. M.S. thesis, University of Guelph, Guelph, Ont.

Richards J. E., R. J. Beamish, and F. W. H. Beamish. 1982. Description and keys for ammocoetes of lamprey from British Columbia, Canada. Canadian Journal of Fisheries and Aquatic Sciences 39:1484-1495. 
Scott, W. B. and E. J. Crossman. 1973. Freshwater fishes of Canada. Canadian Government Publishing Centre, Ottawa, Canada.

Seber, G.A.F. 1982. On The Estimation of Animal Abundance and Related Parameters. $2^{\text {nd }}$ edition. Charles Griffin and Sons, Ltd., London.

Stone, J, T. Sundlov, S. Barndt, and T. Coley. 2000. Evaluate habitat use and population dynamics of lamprey in Cedar Creek. Annual report to Bonneville Power Administration, Project Number 2000-014, Portland, Oregon

Stone, J, T. Sundlov, S. Barndt, and T. Coley. 2001. Evaluate habitat use and population dynamics of lamprey in Cedar Creek. Annual report to Bonneville Power Administration, Project Number 2000-014, Portland, Oregon

Stone, J., J. Pirtle, and S. Barndt. 2002. Evaluate habitat use and population dynamics of lamprey in Cedar Creek. Annual report to Bonneville Power Administration, Project Number 2000- 014, Portland, Oregon.

Torgersen, C. E. and D. A. Close. 2000. Habitat heterogeneity and the spatial distribution of larval Pacific lamprey (Lampetra tridentata) in an Oregon stream. Bonneveille Power Administration, Project Number 94-026, Portland, Oregon.

van de Wetering, S. J. 1998. Aspects of life history characteristics and physiological processes in smolting Pacific lamprey, Lampetra tridentata, in a central Oregon stream. M.S. theses, Oregon State University, Corvallis, Oregon.

Vella, J., L. Steuhrenberg, and T. C. Bjornn. 1999. Migration patterns of Pacific lamprey (Lampetra tridentata) in the lower Columbia River, 1996. Annual Report of Research to the U.S. Army Corp of Engineers, Portland District, Portland, Oregon.

Vella, J., L. Steuhrenberg, and T. C. Bjornn. 2001. Migration patterns of Pacific lamprey (Lampetra tridentata) in the lower Columbia River, 1997. Annual Report of Research to the U.S. Army Corp of Engineers, Portland District, Portland, Oregon.

Vladykov, V. D. and W. I. Follett. 1958. Redescription of Lampetra ayrii (Gunther) of Western North America, a species of lamprey (Petromyzontidae) distinct from Lampetra fluviatilis (Linnaeus) of Europe. J. Fish. Bd. Canada 15:47-77.

Vladykov, V. D. and W. I. Follett. 1965. Lampetra richardsoni, a new nonparasitic species of lamprey (Petromyzonidae) from western North America. Journal of Fisheries Research Board of Canada 22:139-158.

Wydoski, R. S. and R. R. Whitney. 1979. Inland Fishes of Washington. University of Washington Press. Seattle and London. 
Appendix C

Adult Pacific Lamprey Length Statistics and Frequencies in the lower Deschutes River, at Sherars Falls, 2006. 
Appendix A; Table 1. Length (cm) statistics for adult Pacific lamprey collected at Sherars Falls though dipnetting and tribal harvest, 2007.

\begin{tabular}{lcc}
\hline & Marked Lamprey & Harvested Lamprey \\
\hline Sample Size & 209 & 472 \\
Mean Length (cm) & 60.39 & 61.4 \\
Standard Deviation & 3.49 & 4.5 \\
Standard Error & 0.24 & 0.21 \\
C.I. Of Mean & 0.46 & 0.41 \\
Max Length & 70 & 74 \\
Min Length & 51 & 46 \\
Median Length & 61 & 62 \\
Skewness & -0.205 & -0.135 \\
Kurtosis & -0.25 & 0.565 \\
K-S Distribution & 0.0938 & 0.0689 \\
K-S Probability & 0.001 & 0.001 \\
\hline
\end{tabular}




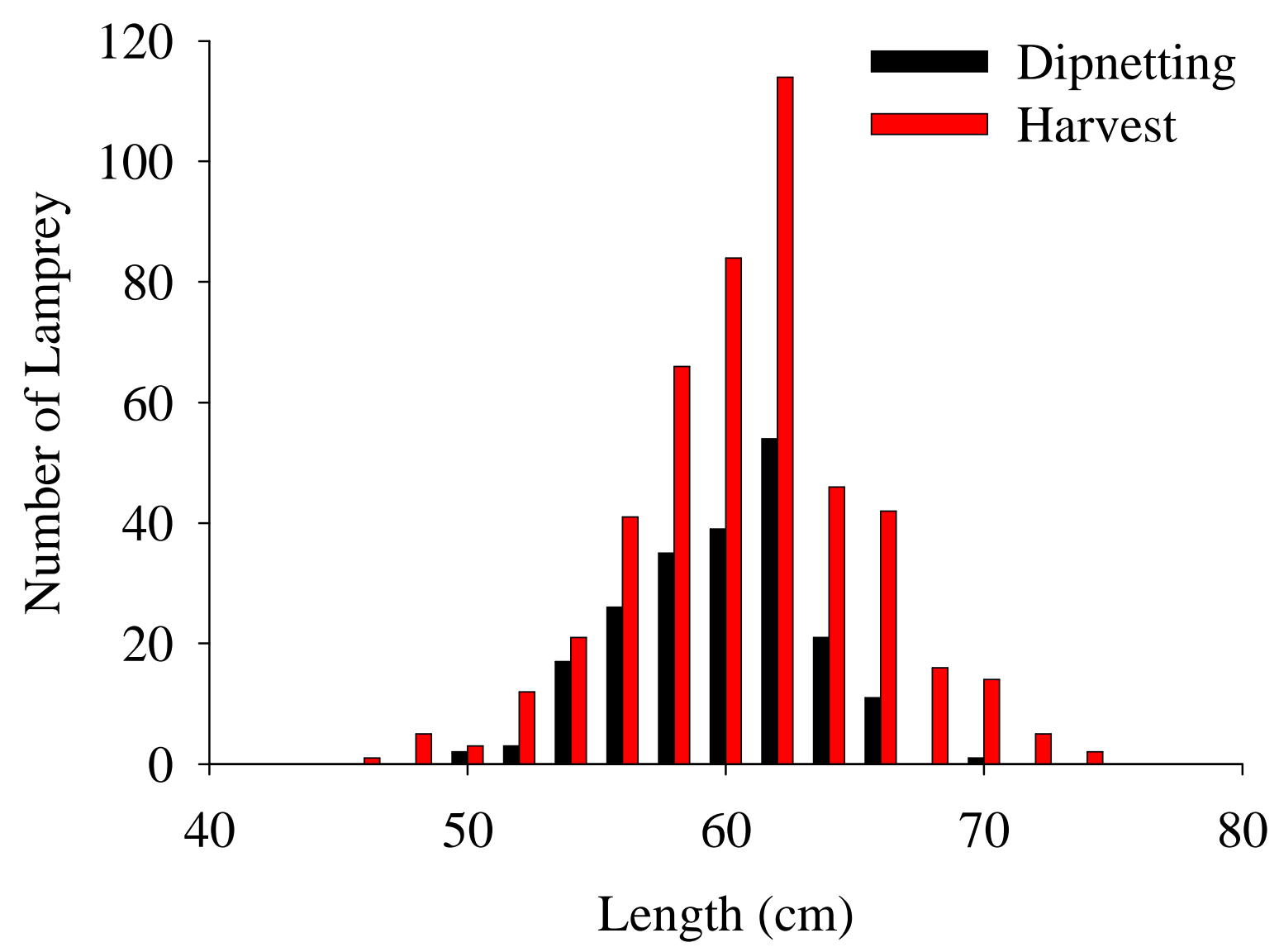

Appendix A; Figure 1. Length frequency for adult Pacific lamprey collected through dipnetting and tribal harvest at Sherars Falls, 2007. 